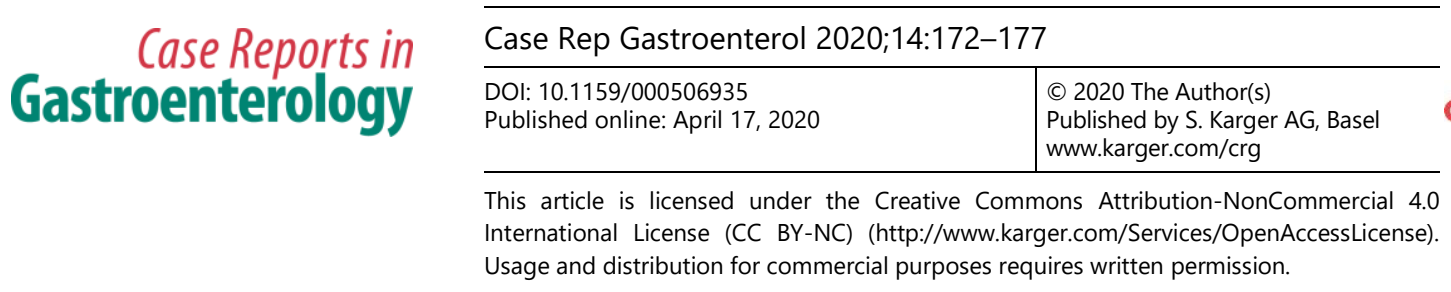

\title{
Ferrous Sulfate-Induced Esophageal Injury Leading to Esophagitis Dissecans Superficialis
}

\author{
Umair M. Nasir ${ }^{\mathrm{a}}$ Brandon Rodgers $^{\mathrm{a}} \quad$ Dayna Panchal $^{\mathrm{a}} \quad$ Catherine Choi $^{\mathrm{a}}$ \\ Shahida Ahmed ${ }^{\mathrm{b}}$ Sushil Ahlawat ${ }^{\mathrm{c}}$ \\ aDepartment of Internal Medicine, Rutgers, New Jersey Medical School, Newark, NJ, \\ USA; ${ }^{b}$ Department of Pathology and Laboratory Medicine, Veterans Affair Hospital, \\ West Orange, NJ, USA; 'Division of Gastroenterology, Department of Medicine, Rutgers, \\ New Jersey Medical School, Newark, NJ, USA
}

\section{Keywords}

Esophagogastroduodenoscopy · Pill esophagitis · Esophagitis dissecans superficialis · Ferrous sulfate

\begin{abstract}
Medication-induced esophagitis is a well-known but relatively rare clinical diagnosis, most common in patients with preexisting esophageal dysmotility, obstruction, or altered anatomy. Esophagitis dissecans superficialis (EDS) is a rare endoscopic finding characterized by sloughing of large fragments of the esophageal mucosal lining. The causes of EDS include prior trauma, heavy smoking history, ingestion of alcoholic and hot beverages, and immunosuppression. We present a unique case of EDS secondary to ferrous sulfate-induced pill esophagitis. The patient was a 94-year-old male who presented with dysphagia to solids, odynophagia, and weight loss. Esophagogastroduodenoscopy (EGD) revealed EDS. Biopsies demonstrated vacuolar degeneration at the midlevel of the epithelium with overlying hyperkeratosis and parakeratosis, with noted black/brown pigment present at the level of the split in the epithelium. The patient was started on a liquid diet with no oral administration of pills. EGD was repeated and showed a significant improvement in esophageal mucosa and resolution of strictures. Although medication-induced esophagitis is not classically associated with EDS, specific circumstances that are associated with pill esophagitis may lead to progression to EDS. In the
\end{abstract}




\section{Case Reports in Gastroenterology}

Case Rep Gastroenterol 2020;14:172-177

DOI: $10.1159 / 000506935$

(c) 2020 The Author(s). Published by S. Karger AG, Basel www.karger.com/crg

Nasir et al.: Ferrous Sulfate-Induced Esophageal Injury Leading to Esophagitis Dissecans Superficialis

case of our patient, prolonged contact of ferrous sulfate to the esophageal mucosa is thought be a result of an enlarged left atrium and pulmonary arteries secondary to longstanding coronary artery disease and an enlarged left bronchus secondary to chronic obstructive pulmonary disease and right pneumonectomy. These anatomical changes likely led to an extended duration of contact and are believed to have led to erosion of the superficial esophageal mucosa, eventually progressing to EDS.

(C) 2020 The Author(s)

Published by S. Karger AG, Basel

\section{Introduction}

Medication-induced esophagitis is a well-known but relatively rare clinical diagnosis, with an incidence of 4 per 100,000 population per year [1]. Patients with preexisting esophageal dysmotility, obstruction, or altered anatomy are more likely to develop medication-induced esophagitis [2]. Common culprits include antibiotics, nonsteroidal anti-inflammatory drugs, potassium chloride, quinidine preparations, iron compounds, bisphosphonates, emepronium, alprenolol, and pinaverium [3, 4]. The most common clinical presentations include retrosternal chest pain, heartburn, odynophagia, and dysphagia. Weight loss and aversion to oral intake represent severe symptoms of esophagitis [5].

Esophagitis dissecans superficialis (EDS), also known as "sloughing esophagitis," is a rare endoscopic finding characterized by sloughing of large fragments of esophageal mucosal lining. The earliest case reports of EDS date back to 1892 and were characterized by Dr. Rosenberg as superficial strips of squamous mucosa that peel off into the esophageal lumen and often are followed by regurgitation of esophageal casts. The causes of EDS include prior trauma, underlying motility disorders, heavy smoking history, ingestion of alcoholic and hot beverages, immunosuppression, and rarely blistering disorders, such as pemphigus vulgaris and bulbous pemphigoid. The histology of EDS can vary depending on the etiology of the case, but the constellation of histological findings includes splitting of the squamous epithelium at different levels above the basal layer, cysts/bullae with intraepithelial cystic degeneration, thick layer of parakeratosis, and basal cell hyperplasia [6]. We present a unique case of EDS secondary to ferrous sulfate tablet-induced pill esophagitis.

\section{Case Description}

The patient was a 94-year-old male with a past medical history of hypertension, hyperlipidemia, iron deficiency anemia, chronic obstructive pulmonary disease, coronary artery disease status post four-vessel bypass, and tuberculosis status post right-sided total pneumonectomy. He presented to the emergency department with a 3-week history of dull/achy, nonradiating, mid-retrosternal chest pains which worsened with swallowing of solids associated with a 5-pound weight loss. On the morning of admission the patient ate a large meal and felt as though the food was lodged in his esophagus. This led to two episodes of nonbilious, nonbloody vomitus and recurrence of the chest pain. Upon admission, vitals revealed a temperature of $36.72^{\circ} \mathrm{C}$, a pulse of 79 beats $/ \mathrm{min}$, a blood pressure of $157 / 69 \mathrm{~mm} \mathrm{Hg}$, a respiratory rate of $20 / \mathrm{breaths} / \mathrm{min}$, and an oxygen saturation of $93 \%$ on $2 \mathrm{~L} / \mathrm{min}$ nasal cannula. Labs were remarkable for decreased hemoglobin of $10.1 \mathrm{~g} / \mathrm{dL}$, with a hematocrit of $29.4 \%$, a mean corpuscular volume of 97.7, and a red blood cell distribution of $13.2 \%$. Arterial blood gas was significant for $\mathrm{PCO}_{2}$ of $53.9 \mathrm{~mm} \mathrm{Hg}$, troponins were $<0.05 \mathrm{ng} / \mathrm{mL}$, and electrocardiography revealed normal sinus rhythm. A computed tomography scan of the chest did not reveal 


\section{Case Reports in Gastroenterology}

Case Rep Gastroenterol 2020;14:172-177

DOI: $10.1159 / 000506935$

c) 2020 The Author(s). Published by S. Karger AG, Basel www.karger.com/crg

Nasir et al.: Ferrous Sulfate-Induced Esophageal Injury Leading to Esophagitis Dissecans Superficialis

external compression of the esophagus, and thus an urgent esophagogastroduodenoscopy (EGD) was done to rule out food impaction. EGD revealed sloughing of esophageal mucosa with blueish discoloration of submucosal layer, dilated esophagus with decreased contraction, and erosive areas of ulceration (Fig. 1). Biopsies were taken in multiple regions of the esophagus. Pathological analysis demonstrated vacuolar degeneration at the midlevel of the epithelium with overlying hyperkeratosis and parakeratosis, with noted black/brown pigment present at the level of the split in the epithelium (Fig. 2). The patient was started on a full liquid diet and on this regimen reported resolution of odynophagia and chest pain. However, soon afterward, he developed acute on chronic hypoxic respiratory failure secondary to aspiration pneumonia as new left lower lung opacity was noted on chest X-ray. At this point the patient was made NPO, started on broad-spectrum antibiotics, placed on bilevel positive airway pressure, and admitted to the intensive care unit. He responded to treatment and was eventually weaned to nasal cannula. EGD was then repeated and showed a significant improvement in the esophageal mucosa and resolution of strictures and ulcerations (Fig. 3). At this point, the patient underwent a swallow evaluation and a modified barium swallow study, which were both negative. Following these results, he was placed on a soft diet which he tolerated well and was discharged home with gastrointestinal follow-up.

\section{Discussion}

Development of medication-induced esophagitis is thought to be secondary to either a disruption of the cytoprotective barrier or a direct irritant effect. Ingested medications can cause disruption of the cytoprotective barrier by reducing the production of the prostaglandin-mediated mucosal lining of the stomach and esophagus. Medications may cause a direct irritant effect if they have prolonged contact time with the esophageal mucosa and possess caustic properties [7]. This is evidenced by the fact that the site of esophageal injury is commonly localized to an area of anatomical compromise, such as the aortic arch, the left atrium and pulmonary arteries, or the gastroesophageal junction [8]. At the level of the aortic arch, the aorta is directly adjacent to the esophagus and the change in planes of the aorta can present as an obstruction to the food bolus in the esophagus. At the level of the mid-esophagus, enlargement and engorgement of the left atrium and pulmonary arteries can externally compress the esophagus, leading to obstruction of intraesophageal contents $[7,8]$. Finally, at the level of the gastroesophageal junction, an incompetent or dysfunctional sphincter may delay or obstruct transit of food material. Although medication-induced esophagitis is not classically associated with EDS, prolonged circumstances typically associated with pill esophagitis may lead to progression to EDS. In the case of our patient, prolonged contact of the ferrous sulfate to the esophageal mucosa is thought be a result of an enlarged left atrium and pulmonary arteries secondary to longstanding coronary artery disease and an enlarged left bronchus secondary to chronic obstructive pulmonary disease and right pneumonectomy. This extended duration of contact is believed to have led to the erosion of the superficial esophageal mucosa, eventually progressing to EDS [7]. This hypothesis is supported by multiple esophageal biopsies revealing black/brown pigmented material, which was later confirmed to be iron particulates, in the epithelium at the level of the splitting. 
Nasir et al.: Ferrous Sulfate-Induced Esophageal Injury Leading to Esophagitis Dissecans Superficialis

\section{Acknowledgement}

The authors would like to thank the Department of Medicine and the Department of Gastroenterology at Rutgers, New Jersey Medical School for their assistance in the development of the drafts and the final manuscript.

\section{Statement of Ethics}

The subject in this case report gave written informed consent to publication of his case, including publication of images. This report did not need IRB approval based on the Department of Health and Human Services criteria.

\section{Disclosure Statement}

The authors have no conflicts of interest to declare.

\section{Funding Sources}

The authors confirm that they have no funding sources to disclose.

\section{Author Contributions}

U.M. Nasir contributed to conception, literature review, drafting, and revision of the article. B. Rodgers contributed to literature review and drafting of the manuscript. D. Panchal contributed to revision of the article. C. Choi contributed to revision of the article and literature review. S. Ahmed contributed to histology figures and histology explanations. S. Ahlawat contributed to endoscopy figures, figure explanations, drafting, and revision of the article.

\section{References}

1 Vãlean S, Petrescu M, Cãtinean A, Chira R, Mircea PA. Pill esophagitis. Rom J Gastroenterol. 2005 Jun;14(2): 159-63.

2 Boyce HW Jr. Drug-induced esophageal damage: diseases of medical progress. Gastrointest Endosc. 1998 Jun;47(6):547-50.

3 Bigard MA, Pelletier AL. Esophageal complications of non steroidal antiinflammatory drugs. Gastroenterol Clin Biol. 2004 Apr;28(Spec No 3):C58-61. French.

4 de Groen PC, Lubbe DF, Hirsch LJ, Daifotis A, Stephenson W, Freedholm D, et al. Esophagitis associated with the use of alendronate. N Engl J Med. 1996 Oct;335(14):1016-21.

5 Longman RS, Remotti H, Green PH. Esophagitis dissecans superficialis. Gastrointest Endosc. 2011 Aug;74(2): 403-4.

6 Carmack SW, Vemulapalli R, Spechler SJ, Genta RM. Esophagitis dissecans superficialis ("sloughing esophagitis"): a clinicopathologic study of 12 cases. Am J Surg Pathol. 2009 Dec;33(12):1789-94.

7 Hey H, Jørgensen F, Sørensen K, Hasselbalch H, Wamberg T. Oesophageal transit of six commonly used tablets and capsules. Br Med J (Clin Res Ed). 1982 Dec;285(6356):1717-9.

8 Kim SH, Jeong JB, Kim JW, Koh SJ, Kim BG, Lee KL, et al. Clinical and endoscopic characteristics of druginduced esophagitis. World J Gastroenterol. 2014 Aug;20(31):10994-9. 


\section{Case Reports in \\ Gastroenterology}

This case report was submitted as an abstract to the American College of Physicians for poster presentation.

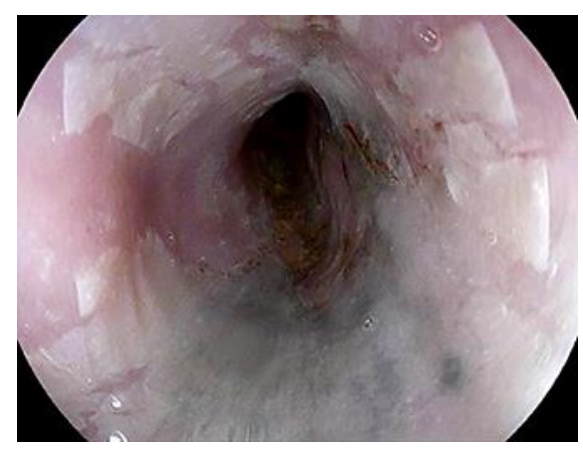

Fig. 1. Esophagogastroduodenoscopy at admission revealing sloughing of large fragments of esophageal mucosa with black/brown pigmentation of esophageal mucosa.

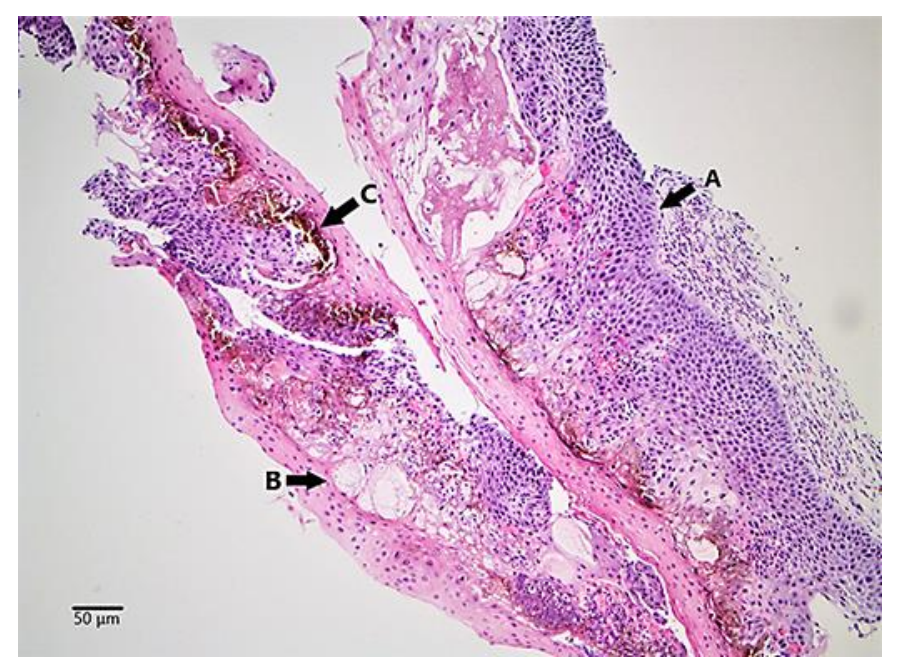

Fig. 2. Low-resolution image of esophageal biopsy with splitting of the squamous epithelium at different levels and basal layer hyperplasia (A), intraepithelial cystic degeneration with variably sized cysts and bullae (B), and black/brown Iron pigment in the basal layer and intraepithelial cystic degeneration (C). 

www.karger.com/crg

Nasir et al.: Ferrous Sulfate-Induced Esophageal Injury Leading to Esophagitis Dissecans Superficialis

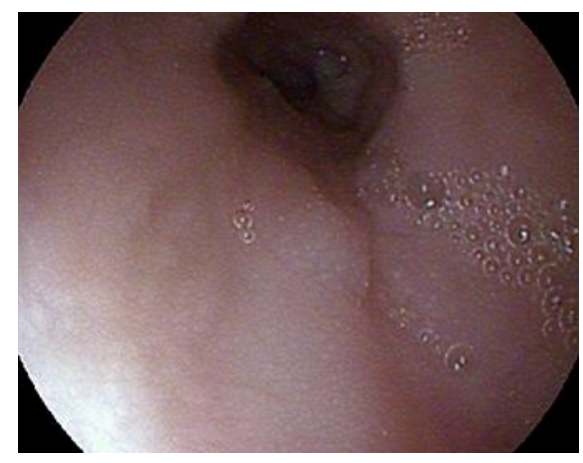

Fig. 3. Esophagogastroduodenoscopy after treatment revealing resolution of black/brown pigmentation of esophageal mucosa with no evidence of esophagitis dissecans superficialis. 